\title{
Methylenetetrahydrofolate Reductase (MTHFR) C677T and A1298C Polymorphisms in Georgian Females with Hypothyroidism
}

\author{
Tamar Kvaratskhelia $^{1,2}$ Elene Abzianidze ${ }^{1} \quad$ Ketevan Asatiani $^{3} \quad$ Merab Kvintradze $^{1}$ Sandro Surmava ${ }^{1}$ \\ Eka Kvaratskhelia ${ }^{1}$
}

${ }^{1}$ Department of Molecular and Medical Genetics, Tbilisi State Medical University, Tbilisi, Georgia

2 Division of Endoctinology, Medical Center "Medimedi," Tbilisi, Georgia

${ }^{3}$ Metabolic Disorders, National Institute of Endocrinology, Tbilisi, Georgia

Address for correspondence Eka Kvaratskhelia, PhD, Department of Molecular and Medical Genetics, Tbilisi State Medical University, Vazha Pshavela Avenue, Tbilisi 0177, Georgia

(e-mail: e.kvaratskhelia@tsmu.edu).

Global Med Genet 2020;7:47-50.
Abstract
Keywords
- hypothyroidism
- hyperhomo- cysteinemia
- MTHFR
- SNPS
- PCR-RFLP

The aim of this study was to investigate the frequency of methylenetetrahydrofolate reductase (MTHFR) gene polymorphisms in Georgian females with hypothyroidism. Thirty-four patients and 29 healthy individuals were recruited in this study. Polymerase chain reaction-restriction fragment length polymorphism analyses were used for genotyping of MTHFR polymorphisms. The results of this study suggest that the MTHFR C677T variant was significantly associated with hypothyroidism. In addition, in individuals with $T$ allele risk of hypothyroidism significantly increased. Combination of $\mathrm{CT} / \mathrm{AA}$ genotypes was more prevalent in the hypothyroid patients than in the control group. Thus, C677T polymorphism could be a possible genetic factor contributing to the pathophysiology of hypothyroidism, possibly through hyperhomocysteinemia.

\section{Introduction}

Methylenetetrahydrofolate reductase (MTHFR) is the trifunctional enzyme catalyzing conversion of 5,10-methylenetetrahydrofolate to 5-methylenetetrahydrofolate, which in turn is the major circulatory form of the folate in the blood and the co-substrate for homocysteine (Hcy) remethylation to methionine. ${ }^{1}$ The MTHFR gene is composed of 11 exons and located on the short arm of the first chromosome (1p36.3). ${ }^{2,3}$ From a total of 65 polymorphisms, two common single nucleotide polymorphism (SNPs) of MTHFR, on the 677th and 1,298th positions, have been described as clinically relevant. ${ }^{4,5} \mathrm{~A}$ common C677T polymorphism at exon 4 causes an amino acid substitution at position 222 from alanine to valine (A222V), thus making the enzyme thermolabile. In homozygous condition, its decreased activity causes the development of mild hyperhomocysteinemia. ${ }^{6,7}$ Another common SNP is an A to C change in position 1298 (A1298C) at exon 7 causing a glutamate to alanine substitution on the 429th position, resulting in decreased MTHFR activity, which is not associated with thermolability of an enzyme. Decreased MTHFR activity is more pronounced in the homozygous state than the heterozygous, and it does not appear to cause hyperhomocysteinemia in either genotype, but its combination with the C677T polymorphism-compound heterozygosity-results in significant elevation of plasma Hcy, even more severe than in 677TT individuals..$^{8-10}$

On the other hand, several studies indicated a higher plasma Hcy levels in patients with hypothyroidism than in healthy, euthyroid individuals, including some experimental studies that indicated decreased MTHFR activity in hypothyroid patients. ${ }^{11}$ Hypothyroidism is usually the primary hypofunction of the thyroid gland resulting in an increase of thyroid-stimulating hormone (TSH) levels in blood; it comprises of two types: subclinical hypothyroidism $(\mathrm{ScH})$ and overt hypothyroidism $(\mathrm{OH})$, according to the extent of decrease in thyroid function. ${ }^{12} \mathrm{ScH}$ is often asymptomatic, only $30 \%$ of the patients may reveal thyroid hormone deficiency symptoms. Also, $\mathrm{ScH}$ is identified in the presence of persistently raising TSH levels and normal free thyroxine (FT4). OH is defined by its clinical symptoms and high levels of TSH combined with decreased levels of thyroid hormone. ${ }^{13,14}$ Hypothyroidism occurs more frequently in women than men. ${ }^{15}$ published online July 20, 2020
DOI https://doi.org/ 10.1055/s-0040-1714091. ISSN 2699-9404.
(C) 2020 Georg Thieme Verlag KG Stuttgart · New York
License terms

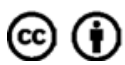


Table 1 Clinical characteristics of the patients at the time of sampling

\begin{tabular}{|l|l|l|}
\hline Variable & Study group & Control group \\
\hline$n$ & 34 & 29 \\
\hline Age & $52.7 \pm 15.6$ & $53.7 \pm 15.2$ \\
\hline TSH $\mathrm{mU} / \mathrm{mL}(\mathrm{N} \mathrm{0.3-4.5)}$ & $11.1 \pm 5$ & $2.7 \pm 1.1$ \\
\hline FT4 $\mathrm{ng} / \mathrm{dL}(\mathrm{N} \mathrm{0.8-1.7)}$ & $1.1 \pm 0.3$ & $1.2 \pm 0.2$ \\
\hline Anti-TPO ab IU/mL $(\mathrm{N}<34)$ & $8.5 \pm 9$ & $6.9 \pm 7.2$ \\
\hline Anti-TG ab IU/mL $(\mathrm{N}<100)$ & $23.7 \pm 25.8$ & $12.3 \pm 15.4$ \\
\hline
\end{tabular}

Abbreviations: FT4, thyroxine; TG, thyroglobulin; TPO, thyroperoxidase; $\mathrm{TSH}$, thyroid stimulating hormone.

Note: Values are presented as absolute numbers, mean \pm SD.

We conducted this study to see whether there is an association between the MTHFR genes' two most common SNPs (C677T and A1298C) and nonautoimmune hypothyroidism.

\section{Materials and Methods}

Ethical approval for the study was granted by the Ethics Committee of Tbilisi State Medical University. Informed written consent for the collection of blood and clinical data, as well as for genetic analysis was obtained from all participants. The study was proposed to subjects admitted to LTD medical center "Medimedi" and the National Institute of Endocrinology. The study group consisted of 34 female members. All patients were diagnosed based on serum levels of TSH, FT4, anti-TG (anti-thyroglobulin), and anti-TPO (antithyroperoxidase) antibodies. In all patients, TSH levels were elevated, with FT4 normal or decreased, and anti-TG and anti-TPO antibodies levels in normal reference ranges (-Table $\mathbf{1}$ ). For the control group, 29 healthy, female volunteers were recruited. None of the controls suffered from hypothyroidism nor had relatives with thyroid diseases.

2.5-mL blood samples were collected in ethylenediaminetetraacetic acid-coated blood collection tubes. Genomic deoxyribonucleic acid (DNA) was isolated from whole blood using DNA blood mini Kit (Qiagen) in accordance with the manufacturer's instructions. DNA was eluted in $200-\mu \mathrm{L}$ elution buffer and stored at $-20^{\circ} \mathrm{C}$ until further analysis.
Nucleic acid samples were checked for concentration by fluorometer (Qubit assays, Thermo Fisher Scientific, Waltham, Massachusetts, United States).

We used polymerase chain reaction (PCR)-restriction fragment length polymorphism analyses for genotyping MTHFR C677T and A1298C polymorphisms. For this, target sequences were amplified using PCR and the product was digested by the addition of restriction enzyme. Each $25-\mu \mathrm{L}$ PCR reaction contained 100-ng genomic DNA, $0.2 \mu \mathrm{M}$ of each primers and Hot Start Taq 2X Master Mix (New England BioLabs). The sequences of forward and reverse primers, PCR conditions, and restriction enzymes used are summarized in -Table 2.

Digestion of PCR products with appropriate restriction enzymes was performed in $50 \mu \mathrm{L}$ of total volume, using $25 \mu \mathrm{L}$ of PCR product, $1-\mu \mathrm{L}$ restriction enzyme, and 5- $\mu \mathrm{L}$ CutSmart buffer. The samples were incubated at $37^{\circ} \mathrm{C}$ for 15 minutes. The DNA samples were loaded in $3 \%$ agarose gel with addition of ethidium bromide (EtBr) that intercalates DNA and makes it visible under ultraviolet (UV) light. A DNA marker with fragments of known length and concentration was running through the gel at the same time as the samples. Electrophoresis was performed at $80 \mathrm{mV}$. Finally, the gel was photographed on an UV transilluminator (Enduro, Labnet Int., NJ, United States).

C677T polymorphism creates a recognition sequence for the Hinfl restriction enzyme, it is detected by the digestion of a 198bp PCR product into two 23bp and 175bp fragments. The 23bp fragment is not visible on the agarose gel. Accordingly, CC wild genotype is characterized by the presence of a 198 bp fragment, TT homozygous polymorphic genotype by 175bp fragment, and CT heterozygous genotype by 198bp and $175 \mathrm{bp}$ fragments. There are two recognition sites for the Mboll restriction enzyme in the A1298C polymorphism. After digestion, the most common AA genotype has three fragments: 28bp, 28bp, and 72bp. The CC homozygous polymorphic genotype is determined by the 100bp fragment and the $\mathrm{AC}$ heterozygous genotype by the presence of both 75bp and 100bp fragments.

Statistical analysis was performed using the Statistical Package for Social Sciences software version 23 (Chicago, Illinois, United States). The data are expressed as mean \pm standard deviation (SD). The frequencies of the alleles and genotypes in patients and controls were compared using chi-square analysis. A $p$-value $<0.05$ was considered as statistically significant. We calculated odds ratio (OR) and 95\% confidence

Table 2 The primers, polymerase chain reaction conditions, and restriction enzymes used in this study

\begin{tabular}{|c|c|c|c|c|}
\hline Gene & SNP & Primer pairs & PCR conditions & Restriction enzymes \\
\hline \multirow[t]{2}{*}{ MTHFR } & C677T & $\begin{array}{l}\text { 5'-TGAAGGAGAAGGTGTCTGCGG-3' } \\
\text { 5'-AGGACGGTGCGGTGAGAGTG-3' }\end{array}$ & $\begin{array}{l}95^{\circ} \mathrm{C} \text { for } 5 \mathrm{~min} \\
\left(95^{\circ} \mathrm{C} \text { for } 30 \mathrm{~s}, 60^{\circ} \mathrm{C} \text { for } 30 \mathrm{~s}, 72^{\circ} \mathrm{C}\right. \\
\text { for } 60 \mathrm{~s}) \times 30 \text { cycles } \\
72^{\circ} \mathrm{C} \text { for } 10 \mathrm{~min}\end{array}$ & Hinfl \\
\hline & A1298C & $\begin{array}{l}\text { 5'-CTTTGGGGAGCTGAAGGACTACTAC-3' } \\
\text { 5'-CACTTTGTGACCATTCCGGTTTG-3' }\end{array}$ & $\begin{array}{l}96^{\circ} \mathrm{C} \text { for } 5 \mathrm{~min} \\
\left(96^{\circ} \mathrm{C} \text { for } 30 \mathrm{~s} 61^{\circ} \mathrm{C} \text { for } 30 \mathrm{~s} 72^{\circ} \mathrm{C}\right. \\
\text { for } 30 \mathrm{~s} \times 40 \text { cycles } \\
72^{\circ} \mathrm{C} \text { for } 5 \mathrm{~min}\end{array}$ & Mboll \\
\hline
\end{tabular}

Abbreviations: PCR, polymerase chain reaction; SNP, single nucleotide polymorphism. 
intervals (CIs) in alleles: $677 \mathrm{C}$ and T; $1298 \mathrm{~A}$ and C; Genotypes -677 CC, CT, TT, CT + TT; 1298 AA, AC, CC, AC+ CC, and combined genotypes-677/1298 CC/AA, CC/AC, CC/CC, CT/AA, $\mathrm{CT} / \mathrm{AC}$, and TT/AA.

\section{Results}

The distribution of C677T and A1298C polymorphism allelic, genotype and combined genotype frequencies in patients with hypothyroidism and healthy controls is shown in - Table 3.

The frequencies of genotypes MTHFR 677CC, 677CT, and 677TT in patients and controls were 47.1, 44.1, 8.8\%, and $86.2,13.8,0 \%$, respectively. As for polymorphism A1298C, the patients and controls presented genotypes 1298AA, 1298AC, and $1298 \mathrm{CC}$ at the following frequencies: $76.5,17.6,5.9 \%$ and $75.9,13.8,10.3 \%$, respectively. Also, we evaluated all possible genotype combinations according to C677T and A1298C polymorphisms in MTHFR-677CC/1298AA, 677CC/ 1298AC, 677CC/1298CC, 677CT/1298AA, 677CT/1298AC, 677CT/1298CC, 677TT/1298AA, 677TT/1298AC, and 677TT/ 1298CC; the frequencies in the case and control groups, respectively, were $32.4,8.8,5.9,35.3,8.8,0,8.8,0,0 \%$ and $69,6.9,10.3,6.9,6.9,0,0,0$, and $0 \%$.

The current study shows an association of MTHFR C677T polymorphism with hypothyroidism as T allele (OR -6.03 ,
95\% CI -1.93 to $18.83, p<0.001$ ), CT genotype (OR $-4.9,95 \%$ $\mathrm{CI}-1.4$ to $17.3, p<0.009)$, and $677 / 1298 \mathrm{CT} / \mathrm{AA}$ combined genotypes (OR $-7.37,95 \% \mathrm{CI}-1.49$ to $36.45, p<0.007$ ) is more prevalent in hypothyroid patients than in the control group. On the other hand, no association was found between A1298C polymorphism and developing hypothyroidism in the case and control individuals.

\section{Discussion and Conclusion}

In this study, we investigated the association between the MTHFR polymorphisms (C677T and A1298C) and hypothyroidism in Georgian population. According to the data of National Center of Disease Control and Public Health of Georgia, ${ }^{16}$ the absolute number of subclinical iodine-deficiency hypothyroidism and other forms of hypothyroidism diagnoses in 2018 was 35,357 and its prevalence was 939.7 per 100,000 . Hypothyroidism affects 4 to $20 \%$ of the adult population, influenced by factors such as age, gender, race, body mass index, and dietary iodine intake. ${ }^{17}$ It should be underlined that all metabolically active cells in the body are targets for thyroid hormones; this is the main reason of the multispectral pattern of hypothyroid condition. ${ }^{18}$ Although detailed pathogenesis of nonautoimmune hypothyroidism remains unclear, bloodbased biomarkers such as dietary folate and Hcy might play

Table 3 Distribution of MTHFR C677T and A1298C polymorphisms and allele frequencies

\begin{tabular}{|c|c|c|c|c|c|}
\hline MTHFR & Genotypes and alleles & Study group $N(\%)$ & Controls $N(\%)$ & OR (95\% Cl) & $x^{2}, p$-Value \\
\hline \multirow[t]{7}{*}{ C677T } & & 34 & 29 & & \\
\hline & $\mathrm{CC}$ & $16(47.1)$ & $25(86.2)$ & $0.14(0.41-0.5)$ & $10.55,0.001$ \\
\hline & $\mathrm{CT}$ & $15(44.1)$ & $4(13.8)$ & $4.9(1.4-17.3)$ & $6.83,0.009$ \\
\hline & TT & $3(8.8)$ & $0(0)$ & $2.8(0.28-28.5)$ & $0.82,0.37$ \\
\hline & $\mathrm{CT}+\mathrm{TT}$ & $18(52.9)$ & $4(13.8)$ & $7.03(2.01-24.6)$ & $10.55,0.001$ \\
\hline & $\mathrm{C}$ & $47(69.1)$ & $54(93.1)$ & $0.17(0.05-0.52)$ & $11.32,0.001$ \\
\hline & $\mathrm{T}$ & $21(30.9)$ & $4(6.9)$ & $6.03(1.93-18.83)$ & $11.32,0.001$ \\
\hline \multirow[t]{6}{*}{ A1298C } & AA & $26(76.5)$ & $22(75.9)$ & $1.03(0.32-3.31)$ & $0.003,0.955$ \\
\hline & $A C$ & $6(17.6)$ & $4(13.8)$ & $1.34(0.34-5.29)$ & $0.174,0.677$ \\
\hline & $\mathrm{CC}$ & $2(5.9)$ & $3(10.3)$ & $0.54(0.08-3.49)$ & $0.427,0.514$ \\
\hline & $\mathrm{AC}+\mathrm{CC}$ & $8(23.5)$ & $7(24.1)$ & $0.97(0.30-3.09)$ & $0.003,0.955$ \\
\hline & A & $58(85.3)$ & $48(82.8)$ & $1.21(0.46-3.14)$ & $1.151,0.698$ \\
\hline & C & $10(14.7)$ & $10(17.2)$ & $0.83(0.32-2.15)$ & $0.151,0.698$ \\
\hline \multirow[t]{9}{*}{ Combined genotypes } & CC/AA & $11(32.4)$ & $20(69)$ & $0.22(0.07-0.63)$ & $8.394,0.004$ \\
\hline & $C C / A C$ & $3(8.8)$ & $2(6.9)$ & $1.31(0.20-8.41)$ & $0.080,0.778$ \\
\hline & $\mathrm{CC} / \mathrm{CC}$ & $2(5.9)$ & $3(10.3)$ & $0.54(0.08-3.49)$ & $0.427,0.514$ \\
\hline & CT/AA & $12(35.3)$ & $2(6.9)$ & $7.37(1.49-36.45)$ & $7.302,0.007$ \\
\hline & $C T / A C$ & $3(8.8)$ & $2(6.9)$ & $1.31(0.20-8.41)$ & $0.080,0.778$ \\
\hline & $\mathrm{CT} / \mathrm{CC}$ & 0 & 0 & - & - \\
\hline & TT/AA & $3(8.8)$ & 0 & - & - \\
\hline & $\mathrm{TT} / \mathrm{AC}$ & 0 & 0 & - & - \\
\hline & $\mathrm{TT} / \mathrm{CC}$ & 0 & 0 & - & - \\
\hline
\end{tabular}

Abbreviations: $\mathrm{Cl}$, confidence interval; SD, standard deviation; OR, odds ratio.

Note: Values are presented as mean \pm SD or $\%$. 
a role in the development of this condition. Morris et al, has reported evidence supporting the correlation between $\mathrm{OH}$ and increased serum Hcy concentration. ${ }^{19}$ The mechanism underlying this correlation remains unknown; however, as inflammation is associated with thyroid dysfunction, oxidative stress induced by the elevated Hcy may be a risk factor for this disease.

MTHFR is a key enzyme in Hcy and folate metabolism. It catalyzes the conversion of 5,10-methylenetetrahydrofolate to 5-methyltetrahydrofolate, the predominant circulating form of folate. MTHFR gene polymorphisms can reduce the concentration of folate in serum, and mildly increase plasma total Hcy. ${ }^{20}$ In the previous study, we found that the C677T SNP in the MTHFR gene may be a genetic risk factor for $\mathrm{ScH}^{21}$ Besides, epigenetic modifications such as DNA methylation may be involved in the pathophysiology of $\mathrm{ScH} .{ }^{22}$

The results of this case-control study suggest that the MTHFR C677T variant, but not A1298C, was significantly associated with hypothyroidism in Georgian women. In addition, in individuals with $\mathrm{T}$ allele risk of hypothyroidism significantly increased (OR $-6.03,95 \% \mathrm{CI}-1.93$ to 18.83 , $p<0.001$ ). We observed that combination of CT/AA genotypes was more prevalent in hypothyroid patients than in the control group (OR $-7.37,95 \% \mathrm{CI}-1.49$ to $36.45, p<0.007$ ). Thus, C677T polymorphism could be a possible genetic factor contributing to the pathophysiology of hypothyroidism possibly through hyperhomocysteinemia.

In summary, early identification of hypothyroidism individuals with MTHFR C677T polymorphism would be very informative for personalized treatment of this condition. We believe that Hcy lowering intervention (with Vitamin B6, B12, and folate) of selected (especially asymptomatic) patients, would be effective for the long-term outcome in treatment of hypothyroidism.

\section{Funding}

None.

\section{Conflict of Interest}

None declared.

\section{Acknowledgment}

We would like to thank all the patients and control subjects who participated in this study.

\section{References}

1 Friso S, Choi SW, Girelli D, et al. A common mutation in the 5,10methylenetetrahydrofolate reductase gene affects genomic DNA methylation through an interaction with folate status. Proc Natl Acad Sci U S A 2002;99(08):5606-5611

2 Goyette P, Pai A, Milos R, et al. Gene structure of human and mouse methylenetetrahydrofolate reductase (MTHFR). Mamm Genome 1998;9(08):652-656

3 Goyette P, Sumner JS, Milos R, et al. Human methylenetetrahydrofolate reductase: isolation of cDNA, mapping and mutation identification. Nat Genet 1994;7(02):195-200

4 Martin YN, Salavaggione OE, Eckloff BW, Wieben ED, Schaid DJ, Weinshilboum RM. Human methylenetetrahydrofolate reductase pharmacogenomics: gene resequencing and functional genomics. Pharmacogenet Genomics 2006;16(04):265-277

5 Selzer RR, Rosenblatt DS, Laxova R, Hogan K. Adverse effect of nitrous oxide in a child with 5,10-methylenetetrahydrofolate reductase deficiency. N Engl J Med 2003;349(01):45-50

6 Biselli PM, Guerzoni AR, de Godoy MF, et al. Genetic polymorphisms involved in folate metabolism and concentrations of methylmalonic acid and folate on plasma homocysteine and risk of coronary artery disease. J Thromb Thrombolysis 2010;29(01):32-40

7 Frosst P, Blom HJ, Milos R, et al. A candidate genetic risk factor for vascular disease: a common mutation in methylenetetrahydrofolate reductase. Nat Genet 1995;10(01):111-113

8 Ogino S, Wilson RB. Genotype and haplotype distributions of MTHFR677C $>$ T and 1298A $>C$ single nucleotide polymorphisms: a meta-analysis. J Hum Genet 2003;48(01):1-7

9 van der Put NM, Gabreëls F, Stevens EM, et al. A second common mutation in the methylenetetrahydrofolate reductase gene: an additional risk factor for neural-tube defects? Am J Hum Genet 1998;62(05):1044-1051

10 Zhang R, Huo C, Wang X, Dang B, Mu Y, Wang Y. Two common MTHFR gene polymorphisms (C677T and A1298C) and fetal congenital heart disease risk: an updated meta-analysis with trial sequential analysis. Cell Physiol Biochem 2018;45(06):2483-2496

11 Zhou Y, Chen Y, Cao X, et al. Association between plasma homocysteine status and hypothyroidism: a meta-analysis. Int J Clin Exp Med 2014;7(11):4544-4553

12 Hollowell JG, Staehling NW, Flanders WD, et al. Serum TSH, T(4), and thyroid antibodies in the United States population (1988 to 1994): National Health and Nutrition Examination Survey (NHANES III). J Clin Endocrinol Metab 2002;87(02):489-499

13 Cantürk Z, Cetinarslan B, Tarkun I, Cantürk NZ, Ozden M, Duman C. Hemostatic system as a risk factor for cardiovascular disease in women with subclinical hypothyroidism. Thyroid 2003;13(10): 971-977

14 Garber JR, Cobin RH, Gharib H, et al; American Association of Clinical Endocrinologists and American Thyroid Association Taskforce on Hypothyroidism in Adults. Clinical practice guidelines for hypothyroidism in adults: cosponsored by the American Association of Clinical Endocrinologists and the American Thyroid Association. Endocr Pract 2012;18(06):988-1028

15 Chaker L, Bianco AC, Jonklaas J, Peeters RP. Hypothyroidism. Lancet 2017;390(10101):1550-1562

16 National Center for Disease Control and Public Health. Subclinical iodine-deficiency hypothiroidism and other forms of hypothyroidism; 2018. Available at: https://www.ncdc.ge/Pages/User/ Documents.aspx?ID=f10b3ffb-da47-4488-94df-2f03764cf365. Accessed April 15, 2020

17 Taylor PN, Albrecht D, Scholz A, et al. Global epidemiology of hyperthyroidism and hypothyroidism. Nat Rev Endocrinol 2018; 14(05):301-316

18 Biondi B, Klein I. Hypothyroidism as a risk factor for cardiovascular disease. Endocrine 2004;24(01):1-13

19 Morris MS, Bostom AG, Jacques PF, Selhub J, Rosenberg IH. Hyperhomocysteinemia and hypercholesterolemia associated with hypothyroidism in the third US National Health and Nutrition Examination Survey. Atherosclerosis 2001;155(01):195-200

20 Brouns R, Ursem N, Lindemans J, et al. Polymorphisms in genes related to folate and cobalamin metabolism and the associations with complex birth defects. Prenat Diagn 2008;28(06):485-493

21 Kvaratskhelia T, Kvaratskhelia E, Kankava K, Abzianidze E. MTHFR gene C677T polymorphism and levels of DNA methyltransferases in subclinical Hypothyroidism. Georgian Med News 2017;(265):19-24

22 Kvaratskhelia T, Kvintradze M, Zarandia M, Kvaratskhelia E, Abzianidze E. Methylation status of the Alu repetitive sequence in subclinical hypothyroidism patients with T677C variant of MTHFR gene. Eur J Hum Genet 2019;27:1911 